\title{
Sophisticated Bidders in Beauty-Contest Auctions
}

\author{
By Stefano Galavotti, Luigi Moretti, and Paola Valbonesi*
}

We study bidding behavior by firms in beauty-contest auctions, i.e., auctions in which the winning bid is the one that gets closest to some function (average) of all submitted bids. Using a dataset on public procurement beauty-contest auctions, we show that firms' observed bidding behavior departs from equilibrium and can be predicted by a "sophistication" index, which captures the firms' capacity of bidding close to optimality in the past. We show that our empirical evidence is consistent with a Cognitive Hierarchy model of bidders' behavior. We also investigate whether and how firms learn to bid strategically through experience. (JEL D22, D44, D83, H57, L12)

T he competition among firms in market economies generates winners and losers: some firms survive, grow up and pay dividends to their shareholders, others have poor performances or go bankrupt and exit the market. Why does this happen? Is it because, though all firms are making their optimal decisions, the winners have some structural or informational advantage over the losers? ${ }^{1}$ Or is it simply because the losers are making the wrong decisions, or, in game-theoretic language, they are not playing their equilibrium strategies?

Answering this question is typically difficult, as we rarely observe all the fine details of the game that firms are actually playing. Moreover, even though we can replicate market games in a controlled lab experiment, it is questionable whether

\footnotetext{
* Galavotti: Department of Economics and Management, University of Padova, via del Santo 33, 35123 Padova, Italy (email: stefano.galavotti@unipd.it); Moretti: Centre d'Economie de la Sorbonne, Université Paris 1 Panthéon-Sorbonne, 106-112 Bvd de l'Hôpital, 75013 Paris, France (email: luigi.moretti@univ-paris1.fr).Valbonesi: Department of Economics and Management, University of Padova, via del Santo 33, 35123 Padova, Italy and Higher School of Economics, National Research University, Moscow-Perm, Russia (email: paola.valbonesi@ unipd.it). We are indebted to Francesco Decarolis for providing us with his codes. We would like to thank for their valuable comments: three anonymous referees, Malin Arve, Alessandra Bianchi, Riccardo Camboni, Ottorino Chillemi, Decio Coviello, Klenio Barbosa, Gordon Klein, Luciano Greco, Marco Pagnozzi, Tim Salmon, Giancarlo Spagnolo, participants at "Workshop on Economics of Public Procurement" (Stockholm 2013), Conference on "Contracts, Procurement, and Public-Private Arrangements" (Florence 2013), 54th Annual Conference of the Italian Economic Association (Bologna 2013), Workshop "How do Governance Complexity and Financial Constraints affect Public-Private Contracts?" (Padova 2014), EARIE Conference (Milan 2014), "1st Berkeley-Paris Organizational Economics Workshop" (2015), seminar participants at PSE \& U. Paris I Panthéon-Sorbonne (2015), Leicester University (2015). The authors declare that they have no relevant or material financial interests that relate to the research described in this paper.

Go to https://doi.org/10.1257/mic.20150240 to visit the article page for additional materials and author disclosure statement(s) or to comment in the online discussion forum.

${ }^{1}$ Asymmetric information across firms is found by Hendricks, Porter, and Boudreau (1987) and Hendricks and Porter (1988) to be the main determinant of success/failure in auctions for oil and gas leases: firms that won previous leases, being better informed on the profitability of neighboring drilling areas auctioned later on, tend to win the most profitable tracts, leaving the least profitable ones to uninformed firms. As a result, the former earn much larger returns than the latter.
} 
and to what extent these insights can be generalized to real-world situations where stakes are large.

In this paper, we address the above question using field data from a particular procurement auction market: average bid auctions. These auctions resemble beauty-contest games in that the winning bid is the one that gets closest to some function (average) of all submitted bids. Average bid auctions have very precise Nash equilibrium predictions that are essentially unaffected by variables that are often unobservable: in equilibrium, either all or-possibly_most bids should be equal. This makes it an ideal setting to investigate possible deviations from equilibrium.

Using an original dataset of procurement average bid auctions in the Italian region Valle d'Aosta, we observe that actual bids significantly depart from equilibrium, being characterized by a systematic heterogeneity. Starting from the consideration that the peculiar rules of these auctions call for refined strategic thinking by bidders, as a bidder has to anticipate the behavior of all other bidders (whereas in a first-price auction, it is sufficient to guess the distribution of the highest competing bid), we hypothesize that the observed heterogeneity could be the result of the interaction of firms with different abilities in performing an iterated process of strategic reasoning, in the spirit of the Cognitive Hierarchy ( $\mathrm{CH}$, henceforth) model by Camerer, Ho, and Chong (2004). We show that, applied to our context and under pretty general assumptions, this model predicts that more sophisticated firms, being able to formulate more accurate beliefs about how others are going to bid, make "better" bids, i.e., closer to the truly optimal one. We then estimate an empirical reduced form model which shows that, in accordance with the main prediction of the $\mathrm{CH}$ model, the firm's sophistication index, measured by her historic record of bidding close to optimality in the past, is strongly and positively correlated to the goodness of that firm's bid, measured by the (negative of the) distance from the truly optimal bid. This result is robust to several specifications of the empirical model; most importantly, it is also confirmed when we focus our analysis on a sample of auctions awarded with a new average bid format, which includes a stochastic component. Interestingly, our evidence shows that a significant learning process is at work: firms become better strategic bidders as they participate in more and more auctions of the same format; instead, sophistication acquired in one format does not significantly affect performance in the other.

This paper mainly contributes to two strands of literature. First, we relate to a few recent papers that fit structural econometric $\mathrm{CH}$ models on real data. In particular, Goldfarb and Yang (2009) study the decision by internet service providers whether or not to adopt the then new 56K modem technology in 1997; Goldfarb and Xiao (2011) investigate the choice by US managers of competitive local exchange carriers (CLECs) to enter local telephone markets after the Telecommunication Act in 1996; Hortaçsu et al. (2017) analyze price-quantity bids in the Texas electricity market. All these papers uncover significant heterogeneity of sophistication among firms/managers, with more sophisticated managers more likely not to adopt the new technology (Goldfarb and Yang 2009), to enter markets with fewer competitors (Goldfarb and Xiao 2011), and to make bids closer to optimality (Hortaçsu et al. 2017). They also show that the level of sophistication is higher for firms operating in larger cities, with more competitors or in markets with more educated populations (Goldfarb and 
Yang 2009), for more experienced, better educated managers (Goldfarb and Xiao 2011, Hortaçsu et al. 2017), for larger firms (Hortaçsu et al. 2017). ${ }^{2}$ Unlike these papers, we do not assume any structural model, but show that the capacity of firms to make better decisions has a systematic component, which goes in a direction coherent with a $\mathrm{CH}$ model.

Second, our paper contributes to a recent empirical and experimental literature on average bid auctions. Decarolis (2014) and Bucciol, Chillemi, and Palazzi (2013) empirically compare the performances of average bid and first-price auctions for the procurement of public works in Italy. These papers show that the first-price is in general associated with lower awarding prices but worse performances in terms of cost and time overruns in the completion time. Conley and Decarolis (2016) argue that the average bid auction is weak to collusion as the members of a cartel, by placing coordinated bids, may pilot the average, thus increasing the probability that one of them wins. Using a dataset (different from ours) of Italian average bid procurement auctions, they find that a large fraction of auctions (no less than 30 percent) is likely to be affected by the presence of cartels; thus, they conclude that the observed deviations from Nash equilibrium are mostly due to a cooperative behavior by bidders. Our paper suggests a complementary explanation to the observed bidding behavior in this type of auctions, but based on a noncooperative argument. Nevertheless, we provide and discuss some arguments supporting the robustness of our findings to the possible presence of collusion. Chang, Chen, and Salmon (2015) experimentally investigate a simple average bid auction with five bidders to assess whether this format can be an effective alternative to first-price auctions for an auctioneer concerned with reducing winner's curse phenomena in common value settings. Their results suggest a positive answer: prices are higher in the average bid than in the first-price auction, thus reducing losses and virtually eliminating default problems. Interestingly, in the average bid auction, subjects do not coordinate on high prices as the Nash equilibrium would predict; rather, they follow a bidding strategy that is strictly increasing in the cost signal. The authors propose an almost-equilibrium explanation of this evidence: while subjects with intermediate signals do best respond to the behavior of the others, subjects with extreme signals misinterpret the informative content of their signal and bid suboptimally. On the other hand, they argue that a level- $k$ model (a variant of the $\mathrm{CH}$ model), though qualitatively consistent, would predict larger bids than observed. In our pretty different environment (we have field data, a different and more complex average bid format and a large number of bidders), instead, the $\mathrm{CH}$ model finds empirical support, and, as we show, this conclusion holds regardless of the firms' specific cost structure (that we do not observe) and of the actual behavior of the unsophisticated (level-0) bidders.

The rest of the paper is organized as follows. In Section I, we illustrate the auction formats considered, describe our dataset, and present some preliminary descriptive evidence. In Section II, we show that our evidence is clearly inconsistent

\footnotetext{
${ }^{2}$ Brown, Camerer, and Lovallo (2012) use a $\mathrm{CH}$ model to explain empirical evidence on box-office premiums associated with cold-opened movies, i.e., movies that are not shown to critics prior to their release. In their paper, consumers, not firms, have limited capacity of strategic thinking and firms exploit the consumers' naïveté to extract more surplus by not disclosing information on the low-quality movies.
} 
with Nash equilibrium, and obtain a testable prediction from a CH model. This prediction leads to the empirical analysis provided in Section III. Section IV offers a discussion of our results, with further supporting evidence and robustness checks. Section V briefly concludes.

\section{Auction Formats and Descriptive Evidence}

Since 1998, the large majority of public works in Italy are procured by means of average bid auctions: these are auctions in which the winner is not the firm that offers the best (i.e., lowest) price, but the one whose offer is closest to some endogenous function (average) of all submitted offers. Participating firms submit a (sealed) price consisting of a percentage discount on the reserve price set by the Contracting Authority (CA). ${ }^{3}$ Once the CA has verified the firms' legal, fiscal, economic, financial and technical requirements, the winning firm is determined according to the following mechanism (see Figure 1, top panel): discounts are ordered from the lowest to the highest and a first average $(A 1)$ is computed by averaging all bids except the 10 percent highest and lowest bids. ${ }^{4}$ Then, a second average $(A 2)$ is computed by averaging all bids strictly above $A 1$ (again disregarding the 10 percent highest bids). The winning bid is the one immediately below $A 2$. In the event that all bids are equal, the winner is chosen randomly. We call this auction format "Average Bid," or simply AB. ${ }^{5}$

Our dataset collects auctions for public works issued by the Regional Government of Valle d'Aosta in the period 2000-2009 (data are from Moretti and Valbonesi 2015). It contains all bids submitted in each auction, together with detailed information at the firm- and auction-level: for each participating firm, we know the identity (i.e., company name) and some characteristics such as size, location, number of pending public procurement projects, and subcontracting position (mandatory or optional, see Moretti and Valbonesi 2015, for a discussion on this); for each auction, we have information on the reserve price, the task of the tendered project and the estimated duration of the work.

An interesting feature of our dataset is that it covers a change in the auction format. In fact, while public works before 2006 were awarded through the $\mathrm{AB}$ format described before, since 2006, and only in Valle d'Aosta, a new average bid awarding mechanism has been introduced. The new format differs from the previous one as it includes a stochastic component; for this reason, we call it "Average Bid with Lottery" auction, or simply ABL. The ABL auction works as follows (see Figure 1,

\footnotetext{
${ }^{3}$ Hence, a higher discount means a lower price paid by the CA. In the rest of the paper, we will use the terms bids and discounts interchangeably.

${ }^{4}$ For example, if there are 20 bids, the 2 lowest and the 2 highest bids are not considered in the computation of $A 1$. When this 10 percent is not an integer, the number of neglected bids is obtained by rounding up: for example, if there are 25 bids, the 3 lowest and the 3 highest bids are not considered.

${ }^{5}$ The AB format was compulsory in Italy until June 2006 for all contracts with a reserve price below 5 million euro. The ratio behind the choice of the $\mathrm{AB}$ format instead of the first-price was the consideration that the former, by softening price competition, would have generated higher awarding prices, thereby reducing the likelihood that, when the ex post cost of realizing the project turns out to be larger than expected, the winning firm declares bankruptcy or asks for a renegotiation of the contract (for more on the trade-off between price and performance in first-price and average bid auctions, see, among others, Cameron 2000; Albano, Bianchi, and Spagnolo 2006; Bucciol, Chillemi, and Palazzi 2013; Decarolis 2014). Starting from 2006, with successive legislative interventions, the possibility for $\mathrm{CAs}$ to adopt the $\mathrm{AB}$ format has gradually and drastically been restricted.
} 

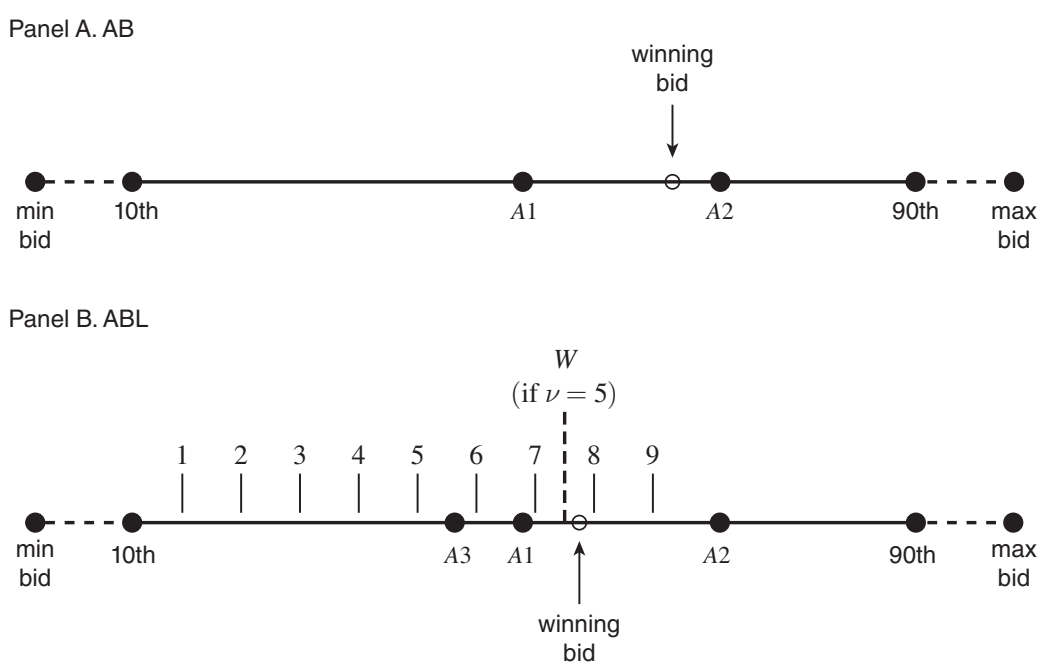

FIGURE 1. AB (top panel) AND ABL (bottom panel) AUCTION

bottom panel): given the average $A 2$ computed as in $\mathrm{AB}$, a random number $(\omega)$ is extracted from the set of nine equidistant numbers between the lowest bid above the first decile of bids and the bid immediately below $A 2$. Averaging $\omega$ with $A 2$, the winning threshold $W$ is obtained and the winning bid is the one closest from above to $W$, provided this bid does not exceed $A 2$. Otherwise, the winner will be the bid equal or closest from below to $W$. Again, if all bids are identical, the winner is chosen randomly. To be precise, if we denote by $d_{10 \%}$ the discount immediately above the first decile of the bid distribution and by $d_{A 2}$ the discount immediately below $A 2$, then the winning threshold is $W=[A 2+\omega] / 2$, where $\omega=d_{10 \%}+\left(d_{A 2}-d_{10 \%}\right) \nu / 10$ and $\nu$ can be any integer between 1 and 9 . Hence, the winning threshold will necessarily fall within an interval whose lower and upper bounds are $\left[A 2+d_{10 \%}+\right.$ $\left.\left(d_{A 2}-d_{10 \%}\right) / 10\right] / 2$ and $\left[A 2+d_{10 \%}+\left(d_{A 2}-d_{10 \%}\right) 9 / 10\right] / 2$, respectively. For reasons that will be clear later on in the paper, we denote the lower bound of this interval by $A 3$.

Figure 2 shows nonparametric kernel density estimation of the bid distributions in the $\mathrm{AB}$ and $\mathrm{ABL}$ formats (dashed line for $\mathrm{AB}$ and straight line for $\mathrm{ABL}$ ). For each auction, discounts have been re-scaled using a min-max normalization (the lowest discount in an auction takes value zero, while the highest takes value one).

Figure 2 highlights two relevant features. First, in either formats, bids are clearly neither uniformly, nor normally distributed. Second, the distributions are clearly asymmetric and different across the two formats: in $\mathrm{AB}$, most bids are concentrated in the right end of the support of the distribution of bids; in ABL, most bids are concentrated below the midpoint of the support.

\section{Theory: Equilibrium versus Cognitive Hierarchy}

The descriptive evidence presented in Figure 2 suggests that the bidding behavior by firms in our dataset is characterized by some regularities. In this section, we 


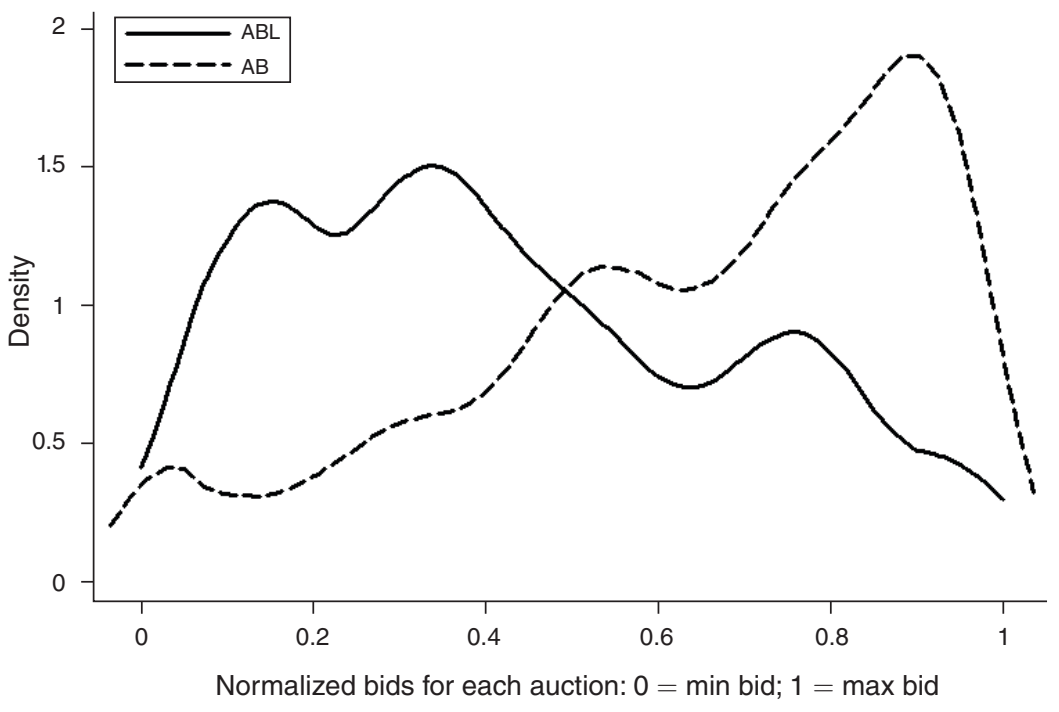

Figure 2. Discounts in AB and ABL: Kernel Density Estimation

first investigate whether this evidence can be consistent with the standard notion adopted to model bidders' behavior in auctions, i.e., Nash equilibrium. To this end, we consider the following (static) model: a single contract is auctioned off through an $\mathrm{AB}$ or $\mathrm{ABL}$ auction. There are $n$ risk neutral firms that participate in the auction. Firm $i$ 's cost of completing the job is given by $c_{i}\left(x_{1}, x_{2}, \ldots, x_{n}\right)$, where $x_{i}$ is a cost signal privately observed by firm $i$ ( $x_{i}$ is the type of firm $i$ ). We assume that firm $i$ 's cost is separable in her own and other firms' signals and linear in $x_{i}$, i.e., that $c_{i}\left(x_{i}, x_{-i}\right)=a_{i} x_{i}+\Gamma_{i}\left(x_{-i}\right)$, with $a_{i}>0, \partial \Gamma_{i} / \partial x_{j} \geq 0$, for all $i, j \neq i$. Firm $i$ 's signal is distributed according to a cumulative distribution function $F_{i}\left(x_{i}\right)$, with full support $\left[\underline{x}_{i}, \bar{x}_{i}\right]$ and density $f_{i}\left(x_{i}\right)$. Signals are independent. The cost functions as well as the signals' distributions are common knowledge. ${ }^{6}$ Firms submit sealed bids formulated in terms of percentage discounts over the reserve price $R$. The winning firm in $\mathrm{AB}$ and $\mathrm{ABL}$ is determined according to the rules described in the previous section. For convenience, the theoretical analysis presented here is carried on under the restriction that all firms always participate in the auction because they always find it worthwhile to do so. Relaxing it would not alter the results, at least qualitatively.

Under the above assumptions, we obtain rather sharp predictions on the (Bayes-) Nash equilibria in the two formats, that we summarize in the following proposition. 7

\footnotetext{
${ }^{6}$ Notice that the model allows for (ex ante) heterogeneity across firms and encompasses the pure private model $\left(\Gamma_{i}=0\right.$, for all $\left.i\right)$ and the pure common value model $\left(c_{i}=c_{j}\right.$, for all $\left.i, j\right)$ as special cases.

${ }^{7}$ For the proof, see the online Appendix. Point (i) was already proved in Decarolis (2018) for the symmetric private value case.
} 
PROPOSITION 1 (Equilibrium):

(i) In the $A B$ auction, there is a unique equilibrium in which all firms submit a 0 -discount (irrespective of their signals).

(ii) In the $A B L$ auction, there exists a continuum of equilibria in which all firms make the same discount d (irrespective of their signals), where d guarantees a positive expected profit even to the firm with the highest expected cost.

(iii) In any equilibrium of the ABL auction, there is a set $K$ of firms of cardinality $k \geq n-\tilde{n}$ that bid $\bar{d}$ with strictly positive probability, where $\bar{d}$ is the largest conceivable bid in the equilibrium and $\tilde{n}$ denotes the smallest integer greater than or equal to $n / 10$. Moreover, if there is (at least) one firm $i \in K$ such that $P W_{i}\left(\bar{d}, \delta_{-i}\right) \geq P W_{i}\left(\bar{d}-\varepsilon, \delta_{-i}\right)$ for $\varepsilon \rightarrow 0^{+}$, the probability that at least $n-\tilde{n}-1$ firms do bid $\bar{d}$ must be larger than $\sum_{j=n-\tilde{n}-1}^{k-1} r^{j} / \sum_{j=0}^{k-1} r^{j}$, where $r$ solves $\sum_{j=1}^{k-(n-\tilde{n}-1)} r^{j}=T$, where $T=(n-\tilde{n})(n-\tilde{n}-2) /(n-\tilde{n}-1)$.

The common feature of the equilibria of both types of auctions is that they all display a very large degree of pooling, both across firms and within firms. The intuition of this result is straightforward: consider a configuration where bids are largely differentiated across and/or within firms (e.g., all bidding functions are strictly decreasing). In this case, the firm/type that makes the highest bid will have a very low (if not zero) probability of winning and would rather reduce her bid to increase it. But if she does so unilaterally, another firm/type will become the highest bidder and would rather reduce her bid as well. This process of "escaping from being the highest bidder" comes to an end only when even the highest bidder herself has a sufficiently large probability of winning.

In the $\mathrm{AB}$ case, this occurs only when all participating firms make a 0-discount (Proposition 1(i)). In fact, the firm/type that makes the highest bid $\bar{d}$ can win the $\mathrm{AB}$ auction only if the winning threshold $W$ coincides with $\bar{d}$ itself and nobody else makes a lower bid (the winning bid is the one closest from below to $W$ ), i.e., only when all firms bid $\bar{d}$. However, if everybody bids $\bar{d}>0$, any firm still has an incentive to deviate downward: doing so, her probability of winning would jump from $1 / n$ to 1 . Only when all firms make a 0 -discount, such a downward deviation is not admissible and we have reached an equilibrium.

In the ABL case, instead, the incentive for the highest bidder to deviate downward stops when there is a sufficiently large probability that a large fraction of the other firms makes the same highest bid as well. This discrepancy with respect to the AB format is not due to the different way in which $W$ is computed, but rather to the fact that in ABL the winning bid is the one closest from above (rather than below) to $W$. To see this, consider a firm/type that makes the highest equilibrium bid $\bar{d}$. Now, if less than $n-\tilde{n}-1$ of the other firms bid $\bar{d}$, the winning threshold will certainly be below $\bar{d}$ : the highest bid $\bar{d}$ can be a winning bid (the winning bid is the one closest from above to $W$, if there is one), but a slight downward deviation $\bar{d}-\varepsilon$ would 
certainly be profitable: the deviating firm would win in the same circumstances as when she bids $\bar{d}$, but now she would be the sole winner in case of winning. If, instead, at least $n-\tilde{n}-1$ of the other firms bid $\bar{d}$, the winning threshold will certainly coincide with $\bar{d}$, and a lower bid will give a 0 -probability of winning the auction. Hence, bidding $\bar{d}$ can be an equilibrium bid only if the probability that at least $n-\tilde{n}-1$ bid $\bar{d}$ is sufficiently large. Proposition 1(iii) states this intuition and provides an explicit lower bound to this probability which is valid when equilibrium satisfies a (mild) restriction: for at least one firm/type that bids $\bar{d}$, the probability of winning should not increase if this firm slightly deviated downward (notice that this restriction is necessarily satisfied when at least one firm has private cost or when at least one firm's bidding function is continuous at $\bar{d}$ ). To get an idea of the size of this lower bound, notice that if $n=20$, the probability of observing at least 17 equal bids (at $\bar{d}$ ) must be grater than 90.1 percent. $^{8}$

The previous argument should also make it clear why, in these auctions, cost signals do not matter much. The point is that, unlike a standard auction, where a higher bid always increases the probability of winning and thus stronger bidders - those with better signals - will bid higher, here, to increase the probability of winning a bidder has to make a bid that is neither too high nor too low. Hence, having a better signal is much less of an advantage than in a standard auction. As a consequence, the cost structure plays a less important role in shaping the equilibrium. 9

Now, looking at our data, we can rather safely claim that the theoretical predictions described above are inconsistent with the empirical evidence. In the AB auction, bids are far from being equal (the standard deviation of the distribution of bids is, on average, 4.6 percent) and are significantly greater than zero (the average discount is 18.0 percent), while equilibrium predicts all bids equal to zero (Proposition 1(i)). ${ }^{10}$ In the ABL auction, we can safely reject the all-equal-bids equilibrium of Propesition 1(ii) (in ABL, the average standard deviation of the distribution of bids is 3.6). ${ }^{11}$ Moreover,

\footnotetext{
${ }^{8}$ With interdependent costs, the restriction in Proposition 1(iii) is not necessarily satisfied, as one firm may still find it unprofitable to slightly deviate downward even if in doing so her probability of winning increases: this might be the case if the downward deviation increases the probability of winning when the other firms has worse signals and thus increases the expected cost upon winning. However, if the cost functions are not dramatically affected by a marginal change in the other firms' signals, then the lower bound should be of the same order as the one stated in Proposition 1(iii).

${ }^{9}$ This line of reasoning applies not only to production costs but, more generally, to any other element that can affect the competitiveness of a firm in the auction. For example, Decarolis (2014) and Zheng (2001) argue that, in procurement first-price auctions where the true production costs are known only ex post, riskier firms-those with lower default costs-make higher discounts, thus generating an adverse selection effect. Our model immediately adapts to an environment where firms differ in their default costs, thus predicting that this adverse selection effect almost disappears in average bid auctions.

${ }^{10}$ Hence, if firms had always played the Nash equilibrium, the CA would have paid much more for the works. In particular, given that, in our sample, the average reserve price is about 1 million euro and the average winning discount is 18 percent, the average additional payment by the CA for each project would have been about 180,000 euro. Moreover, given that, in the Nash equilibrium, the winner is chosen randomly, the expected market share and market power of each firm would have been the same.

${ }^{11}$ In the ABL auction, given the multiplicity of equilibria, there is a potential problem of coordination, and one could object that our evidence is just the result of a coordination failure. However, this explanation does not seem fully convincing: first, it would apply to the $\mathrm{ABL}$ format only, leaving the observed behavior in $\mathrm{AB}$ unexplained; second, even restricting this explanation to the ABL case, the observed regular asymmetry in the distribution of bids would raise the following question: why do many firms reach a good coordination on relatively low discounts, whereas other firms seems totally unable to coordinate?
} 
according to Proposition 1(iii), in ABL, we should expect to observe a concentration of bids in the right tail of the distribution. This is clearly at odds with our descriptive evidence, according to which the typical bid distribution in an ABL auction has its mode below the midpoint of the range of bids.

Thus, we conclude that Nash equilibrium does not seem to be a correct modeling hypothesis for the bidding behavior of firms in our dataset. Although we do reject the equilibrium hypothesis that all firms are bidding optimally, our intuition is that some of them are doing so, while others are not. One model that supports this intuition is the $\mathrm{CH}$ model. This model has been introduced by Stahl and Wilson $(1994,1995)$ and further developed and applied by, among others, Camerer, Ho, and Chong (2004). Strictly related to the CH model is the level- $k$ model introduced by Nagel (1995) and applied to first- and second-price auctions by Crawford and Iriberri (2007) and Gillen (2009). The CH model has proved to be particularly fruitful in explaining experimental evidence in beauty-contest games (see the thorough survey by Crawford, Costa-Gomes, and Iriberri 2013). Since average bid auctions are nothing but incomplete information versions of beauty-contest games, this model is a natural candidate to explain our evidence.

The $\mathrm{CH}$ model holds that individuals (players) involved in strategic situations differ by their level of sophistication, i.e., their ability of performing an iterated process of strategic thinking. The proportion of each level in the population is given by a frequency distribution $P(k)$, where $k=0,1,2, \ldots$ is the level of sophistication. Level-0 players are completely unsophisticated and simply play randomly (according to some probability distribution, in general uniform); a level- $k$ player, with $k \geq 1$, believes that her opponents are distributed, according to a normalized version of $P(k)$, from level-0 to level- $(k-1)$, and chooses her optimal strategy given these beliefs. For example, a level-1 player believes that all her opponents are of level-0; a level- 2 player believes that her opponents are a mixture of level-0 and level-1 players, where the proportion of level-0 players is $P(0) /(P(0)+P(1))$; and so on. In other words, a level- $k$ player's strategy is optimal conditional on her beliefs, but since her beliefs do not contemplate the presence of players of the same or higher level, the resulting strategy will in general be suboptimal. Clearly, a player with a higher level of sophistication has in mind a more comprehensive picture of how other players think and play; hence, we expect her strategy to be closer to the optimal one.

The logic behind the $\mathrm{CH}$ model seems particularly appropriate in our context. In an average bid auction, all bids affect the position of the winning threshold. Therefore, it is crucial to have correct guesses on how all other firms are going to bid. But predicting the behavior of all other firms involves answering a complicated chain of questions of the kind: what bid $b$ will a firm make if she thinks others are going to bid $a$ ? And what bid $c$ will a firm make if she anticipates that others are going to bid $b$ because they think others are going to bid $a$ ? And so on. Firms that are able to push this chain of reasoning further will have an advantage over those that perform less steps of such reasoning, in the sense that they will end up with more precise predictions on the actual behavior of others. As a consequence, they are expected to make better (i.e., closer to optimality) bids. 
Solving the $\mathrm{CH}$ model in our context for a generic number of firms is problematic. ${ }^{12}$ Therefore we rely on an asymptotic analysis: this seems sufficiently appropriate in our case, given that the number of participating firms in our dataset is, on average, relatively large (about 53 in $\mathrm{AB}$, about 83 in $\mathrm{ABL}$ ); moreover, we believe that the intuition provided by the asymptotic analysis applies in general, at least under standard hypothesis about the behavior of level-0 firms.

Now, let $P(k)=p_{k}, k \geq 0$, be the proportion of level- $k$ firms and suppose that level-0 firms (independently) choose their bids from the bid distribution $G_{0}(d)$ with density $g_{0}(d)$ and full support $[\underline{d}, \bar{d}]$. Solving the $\mathrm{CH}$-model for $n \rightarrow \infty$, we obtain the following main prediction. ${ }^{13}$

PROPOSITION 2 (Cognitive Hierarchy): In the AB auction, in the limit, the (expected) distance of a firm's bid from A2 is strictly decreasing in her level of sophistication. In the ABL auction, in the limit, the (expected) distance of a firm's bid from A3 is strictly decreasing in her level of sophistication. ${ }^{14}$

The previous result is pretty intuitive. Consider the $\mathrm{AB}$ auction: denote by $A 2_{j}$ and $A 1_{j}$ the random variables corresponding to the averages $A 2$ (the winning threshold) and $A 1$, conditional on the fact that firms' levels range from 0 to $j$ (and let $\overline{A 2}_{j}$ and $\overline{A 1}_{j}$ be their expectations). A level- $k$ firm believes that the other firms range from level 0 to $(k-1)$; hence, to formulate her optimal bid $\delta_{k}$, she computes the probability distribution of $A 2_{k-1}$ (which, in turn, depends on $A 1_{k-1}$ ): the intuition suggests that, typically, $\delta_{k}$ will be "close" (from below) to $\overline{A 2}_{k-1}$. Now, if $\delta_{k}$ is indeed close to $\overline{A 2}_{k-1}$ and given that, by construction, $\overline{A 2}_{k-1}$ is larger than $\overline{A 1}_{k-1}$, then $A 2_{k}$ and $A 1_{k}$, that incorporate also level- $k$ firms' bids $\delta_{k}$, will be larger than $A 2_{k-1}$ and $A 1_{k-1}$ : thus, $\delta_{k+1}$, which is close to $\overline{A 2}_{k}$, will be larger than $\delta_{k}$. And so on. Hence, firms' bids will be strictly increasing in their level of sophistication; or, equivalently, the distance from $\overline{A 2}$ - the expected value of the true winning threshold, i.e., the one computed on the basis of the true distribution of levels in the population of firms ${ }^{15}$ - will be strictly decreasing. Proposition 2 states that the intuition described above is correct asymptotically. In fact, when $n$ grows to infinity: (i) the impact of any firm's bid on $A 2$ is negligible; (ii) the probability distribution of $A 2_{k}$ converges to its expected value $\overline{A 2}_{k}$; (iii) there is a very high probability that at least one level-0 firm bids close to $\overline{A 2}_{k}$. Hence, the optimal bid of a level- $k$ firm converges to $\overline{A 2}_{k}$. However, we believe that this result holds also for generic values of $n$, at least under standard assumptions on $G_{0} \cdot 16$

\footnotetext{
${ }^{12}$ Chang, Chen, and Salmon (2015), who experimentally studied a simpler average bid auction, focused their theoretical analysis on the case of three bidders because "the explicit formulation of a bidder's winning probability for a general $n$-bidder game is difficult, if not impossible, to obtain for $n \geq 4$ " (p. 1241).

${ }^{13}$ For the proof, see the online Appendix. Notice that, apart from the assumption of full support for $G_{0}$, we do not make any hypothesis on the shape of $P$ and of $G_{0}$.

${ }^{14}$ The second statement holds only under a very mild assumption on the distribution of level-0 firms' bids. In some (exceptional) cases, it is possible that the (expected) distance of a firm's bid from $A 3$ is constant in her level of sophistication.

${ }^{15}$ Thus, $\overline{A 2}$ is nothing but $\overline{A 2}_{\bar{k}+1}$, where $\bar{k}$ is the maximum sophistication level in the population of firms.

${ }^{16}$ We performed a series of numerical simulations for different values of $n$. The results are consistent with the (asymptotic) result of Proposition 2 (see the online Appendix).
} 
The same intuition applies also to the ABL auction: here, a level- $k$ firm, upon choosing her optimal bid, must compute the probability distribution of $A 3_{k-1}$ and $A 2_{k-1}$, i.e., the lower and upper bounds of the interval from which the winning threshold will randomly be drawn. Given that any number in this interval has the same probability to be drawn, we expect a level- $k$ firm to make a bid closer to the expected value (from her viewpoint) of the lower bound: $\overline{A 3}_{k-1}$. Then, we can apply the same reasoning described above. In this case, however, depending on the distribution of level-0 firms' bids, bids can be strictly increasing (this occurs when $\overline{A 3}_{0}>\overline{A 1}_{0}$ ) or strictly decreasing (this occurs when $\overline{A 3}_{0}<\overline{A 1}_{0}$ ) in the level of sophistication of firms. We expect the latter to be the canonical case: for example, if $G_{0}$ is symmetric, then $\overline{A 3}_{0}$ is necessarily lower than $\overline{A 1}_{0}$. In both cases, anyway, the distance from the true expected value of $A 3$ is strictly decreasing.

\section{Empirical Analysis}

The previous section has shown that, in our context, the $\mathrm{CH}$ model implies that, if firms have different sophistication levels, this should reflect in different bids by them. An heterogeneity in bidding behavior is indeed apparent in our data (see Figure 2); however, deeper statistical analysis is needed to asses whether such heterogeneity is related to firms' sophistication in the direction prescribed by the $\mathrm{CH}$ model, namely that more sophisticated firms bid closer to the (expected) value of $A 2$ in $\mathrm{AB}$, of $A 3$ in $\mathrm{ABL}$ (Proposition 2). However, to empirically test Proposition 2, we first need to measure firms' sophistication level.

\section{A. A Measure of Firms' Sophistication}

In accordance with the fundamental idea of the $\mathrm{CH}$ model, a measure of firms' (i.e., managers') sophistication should capture their ability of thinking strategically in interactive situations. Needless to say, measuring this ability is a complicated task. One possibility would be to rely on some instruments, like some measure of ability, education or professional achievements of firms' managers. ${ }^{17}$ We refrain from following this strategy for two reasons. First, we lack information on firms' managers or other firms' characteristics that may proxy strategic ability. Second, and most importantly, although innate and/or previously acquired skills certainly matter, the intuition and the literature suggest that individuals can learn to think strategically in games as they play over and over again. ${ }^{18}$ Hence, in a context like ours in which we observe the same firms bidding repeatedly, an out-of-sample static

\footnotetext{
${ }^{17}$ In experimental beauty-contest games, Burnham et al. (2009) and Brañas-Garza, García-Muñoz, and González (2012) showed that subjects who obtained higher scores in a psychometric test of cognitive ability performed better, while Chen, Du, and Yang (2014) showed that subjects' working memory capacity is positively related to their $\mathrm{CH}$ level. Goldfarb and Xiao (2011), who fitted a $\mathrm{CH}$ model to the entry decisions by managers in the US local telephone markets, uncovered a significant positive relationship between managers' strategic ability on the one hand, and their education and experience as CEOs on the other.

${ }^{18}$ Gill and Prowse (2016), studying how cognitive ability (and character skills) influence learning to play equilibrium in a repeated $p$-beauty contest game, find that more cognitively able subjects make a choice closer to equilibrium, converge more frequently to equilibrium play, and earn more even as behavior approaches the equilibrium prediction.
} 
measure of sophistication would miss this learning component. Instead, we need a measure of sophistication that can change dynamically within the sample. To this end, we follow a completely different approach: for each auction in our sample, we measure a firm's sophistication by the complement to one of the relative distance of that firm's bids from $A 2$ in $\mathrm{AB}$, from $A 3$ in $\mathrm{ABL}$, in the preceding auctions of that format which she participated in. The idea is that, if the $\mathrm{CH}$ model is indeed a good model of firms' bidding behavior, then we can "invert" the prediction of Proposition 2 and take the distance from $A 2$ or $A 3$ as an outcome-based measure of her capacity of thinking strategically. ${ }^{19}$

Specifically, the sophistication index of firm $i$ at the moment in which she participates in the $\mathrm{AB}$ auction $j$ is computed as

$$
\text { BidderSoph }_{i j}^{A B}=\sum_{k \in \mathcal{A} \mathcal{B}_{i j}}\left(1-\frac{\Delta_{i k}-\Delta_{k}^{\min }}{\Delta_{k}^{\max }-\Delta_{k}^{\min }}\right),
$$

where $\mathcal{A B}_{i j}$ is the set of past $\mathrm{AB}$ auctions that took place before auction $j$ in which firm $i$ participated, $\Delta_{i k}$ is the distance of firm $i$ 's bid from the realized value of $A 2$ in auction $k$, and $\Delta_{k}^{\min }$ and $\Delta_{k}^{\max }$ are the distances from $A 2$ of the closest and furthest bid submitted in auction $k$. Notice that each term in the summation in (1) is between 0 and 1 and takes value 0 (1) if firm $i$ 's bid was the furthest from (closest to) $A 2$ in that auction. The term BidderSoph $h_{i j}^{A B L}$ - the sophistication index of firm $i$ at the moment in which she participates in the ABL auction $j$-is defined similarly, with the caveat that, in this case, the $\Delta \mathrm{s}$ are distances from $A 3$.

The sophistication index (1) is clearly dynamic, as it changes from one auction to the next depending on the outcome of the last auction. Hence, it allows a firm's level of sophistication to increase or decrease relative to the others. The idea is that firms may learn to think strategically as they gain experience in the auction mechanism. Similarly, a firm may lose positions in the sophistication ranking if she does not take into account that other firms may become better strategic thinkers through learning. Notice that our sophistication index is auction format-specific, in the sense that participations to AB do not contribute to the firm's sophistication index when she bids in ABL. The idea is that what matters is not experience per se, but experience in that particular strategic situation. 20

Figure 3 shows the distributions of bids in AB and ABL for highly and lowly sophisticates firms (i.e., firms with sophistication index above the ninetieth percentile versus those with sophistication index below the tenth percentile). These graphs point out a heterogeneity in bidding behavior that goes in the direction suggested by Proposition 2. In particular: (i) bids by highly sophisticated firms are more concentrated than those by lowly sophisticated ones; and (ii) highly sophisticated firms'

\footnotetext{
${ }^{19}$ In some sense, we are adopting an approach similar to revealed preference: we derive the determinants of behavior by induction from the behavior itself.

${ }^{20}$ The use of a measure of a firm's sophistication that weighs all previous participations not only allows to take into account that a firm may learn to think strategically through experience, but also gives more robustness to the results: in a single auction, a firm may bid close to optimality by chance; in a series of auctions, a firm systematically bids close to optimality only if she is a good strategic thinker. By using a cumulative measure, the impact of lucky bids results downsized.
} 
Panel A

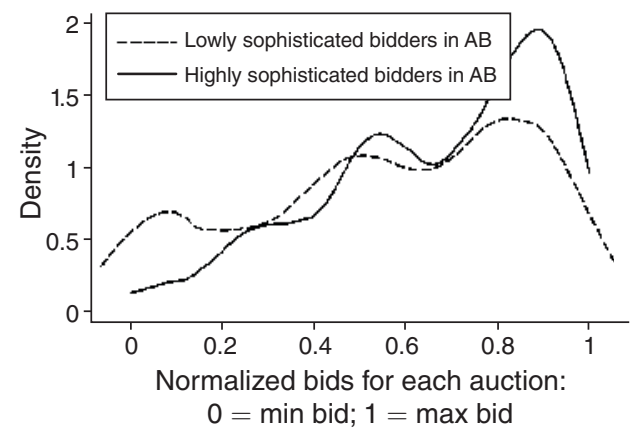

Panel B

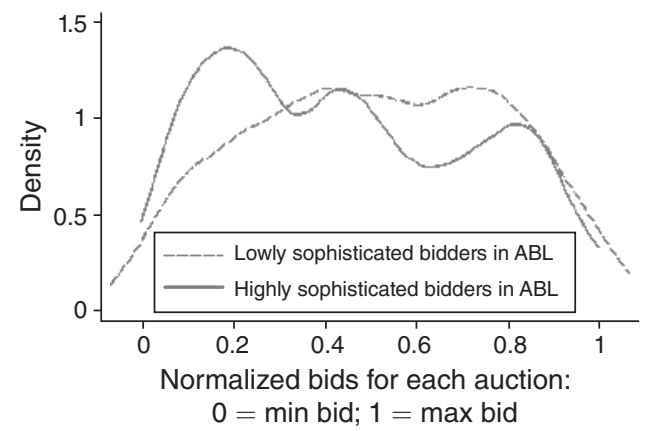

Figure 3. Discounts In AB (left panel) AND ABL (right panel) FOR Highly AND Lowly Sophisticated Firms: KERNEL DENSITY ESTIMATION

bids are concentrated in the right tail of the distribution of bids in $\mathrm{AB}$ and in the left tail in ABL. ${ }^{21}$

Given that our sample contains (by far) more AB than ABL auctions, the average value of the sophistication index is, by construction, larger in AB. Looking at the whole sample, the frequency distribution of the index displays a higher concentration on low values and fewer observations on high values in both formats, indicating that there are few firms making good bids in a large number of auctions. However, looking only at late years, the distribution tends to be smoother, suggesting that, after some time, more and more firms reach relatively high levels of their sophistication. ${ }^{22}$

\section{B. Estimated Equation}

Given the measure of firms' sophistication just illustrated, we can now introduce and estimate a reduced form model to test Proposition 2. The model is the following (we omit the dependence on the auction format, but it is intended that there is one such equation for each format):

$$
\log \mid \text { Distance }_{i j} \mid=\alpha+\beta \log \left(\text { BidderSoph }_{i j}\right)+\gamma F_{i}+\sigma F A_{i j}+\theta A_{j}+\epsilon_{i j}
$$

In (2), the dependent variable, $\log \mid$ Distance $_{i j} \mid$, is the logarithm of the difference (in absolute value) between firm $i$ 's bid in auction $j$ and the realized value of $A 2[A 3]$ in that $\mathrm{AB}[\mathrm{ABL}]$ auction. Here, BidderSoph $h_{i j}$ is firm $i$ 's sophistication index at the moment of participation in auction $j$, as defined by (1). ${ }^{23}$ The term $F_{i}$ represents a

\footnotetext{
${ }^{21}$ A two-sample Kolmogorov-Smirnov test confirms that the bid distributions for highly and lowly sophisticated firms are statistically different in both auction formats.

${ }^{22}$ See Figures D1 and D2 in the online Appendix. See also Figure D3 in the online Appendix, which shows the distribution of the sophistication index in $\mathrm{AB}$ auctions by firm size and period. Interestingly, distributions have similar shapes across firm sizes, although small firms reach lower levels of sophistication by the end of the period.

${ }^{23}$ We adopt a log-log model for two reasons. First, the theoretical analysis suggests a nonlinear relationship between sophistication and distance from $A 2$ or $A 3$. Second, a log-log model allows to interpret the coefficient attached to the sophistication index as an elasticity. Notice that observations with a sophistication index equal to zero are excluded as we require firms to show their bidding ability at least once before entering in the analysis. Our main
} 
set of characteristics of firm $i$ that do not vary over time, including proxies for size and location. ${ }^{24}$ The variable $F A_{i j}$ is a set of firms' characteristics that can vary for each auction. This set includes the backlog of works (i.e., the number of pending public procurement projects a firm has at the moment she bids in auction $j$; it is a proxy for capacity constraints) and the subcontracting position. The term $A_{j}$ is a set of variables to control for the characteristics of the auction, such as dimension and complexity of the auctioned work, ${ }^{25}$ and the timing of the auction (i.e., year dummy variables to adjust for temporal shocks to the firms and the CA).

To reduce concerns about omitted variable problems affecting the relationship between the sophistication index (which is built upon firms' past behavior in auctions of that format) and firms' current behavior (e.g., some factors that may influence both the past and current performance of firms are not controlled for), in some specifications we also included firm-fixed effects to adjust for firm-specific characteristics. This enables us to focus on the within-firm variation in the sophistication status. However, some relevant characteristics of the firms could vary over the time horizon of our analysis. For this reason, in some specifications we also add firm-year-fixed effects, thus controlling for those characteristics that can vary over time, like, for instance, productivity, financial position, and management skills. This set of fixed effects represents a suitable substitute for the inclusion of firm-year control variables that can be recalled from balance-sheets. ${ }^{26}$

\section{Description of the Sample}

Table 1 shows summary statistics of the sample used in our estimations, broken down by auction format. ${ }^{27}$ The sample of $232 \mathrm{AB}$ auctions includes 8,927 bids made by 514 different firms; the sample of $28 \mathrm{ABL}$ auctions includes 1,501 bids made

results do not change when we include firms with a sophistication index equal to zero (using $\log (1+$ BidderSoph) as a regressor) or when we adopt a log-linear specification (see the online Appendix, Table D1).

${ }^{24}$ Because we do not have data on firms' employees or total assets, we construct proxies for firms' size based on the type of business entity: Small = one-man businesses, limited and ordinary partnerships; Medium = limited liability companies; Large + cooperatives $=$ public corporations and cooperatives. The use of these proxies is motivated by the evidence of a positive correlation between the type of business entity and the size of Italian firms (see Moretti and Valbonesi 2015, and Coviello et al. 2018). To proxy firms' location, we take the geographical distance between Aosta (the seat of the CA) and the chief town of the province where the firm has her headquarters (we assign a distance of 30 kilometers to firms located in Valle d'Aosta, see Moretti and Valbonesi 2015). This variable is also a proxy for firms' costs (at least for the roadwork contracts, which represent the majority of our auctions). We thank an anonymous referee for suggesting this.

${ }^{25}$ In the procurement literature, the complexity of a project is usually proxied by its value or the auction's reserve price, the expected contractual duration of works, dummies for the type of work included in the project. We use all these proxies in our estimation. Notice that the contract value is determined by an engineer employed by the CA, according to a price list that enumerates the standardized costs for each type of work (see Decarolis 2014, and Coviello and Mariniello 2014, for details on how the CA determines this price). Similarly, the expected duration of the work is computed by a CA's engineer and is stated in the call for tender.

${ }^{26}$ The presence of small and micro firms in our dataset makes it impossible for us to use balance sheet information to construct additional controls or instrumental variables as these firms are typically underrepresented in firm-level balance-sheet-based databases. In fact, a large number of firms is unmatched when we try to merge our dataset with the Bureau Van Dijk's Aida database of Italian firms.

${ }^{27}$ These descriptive statistics refer to the sample used for the empirical analysis proposed in this section. The original sample was larger. The sophistication index, the dependent variable, and other control variables are computed on this larger sample to avoid being influenced by partial observations. However, due to missing values in some control variables, our regression analyses are based on the restricted sample. 
TABLE 1 -Summary Statistics

\begin{tabular}{|c|c|c|c|c|c|c|}
\hline & \multicolumn{3}{|c|}{$\mathrm{AB}$} & \multicolumn{3}{|c|}{$\mathrm{ABL}$} \\
\hline & Observations & Mean & SD & Observations & Mean & SD \\
\hline \multicolumn{7}{|l|}{ Firm-auction level } \\
\hline $\mid$ Distance $\mid$ & 8,927 & 1.555 & 2.437 & 1,501 & 1.433 & 1.990 \\
\hline BidderSoph & 8,927 & 24.789 & 24.699 & 1,501 & 4.192 & 3.954 \\
\hline Backlog & 8,927 & 2.857 & 7.143 & 1,501 & 2.005 & 4.963 \\
\hline Optional subcontracting & 8,927 & 0.871 & 0.336 & 1,501 & 0.817 & 0.387 \\
\hline \multicolumn{7}{|l|}{ Auction level } \\
\hline Reserve price (euro) & 232 & $1,120,365$ & 895,493 & 28 & $1,109,662$ & 681,532 \\
\hline Expected duration (days) & 232 & 301.431 & 166.172 & 28 & 402.857 & 177.353 \\
\hline Number of bidders & 232 & 53.216 & 28.613 & 28 & 82.857 & 41.662 \\
\hline Building construction & 232 & 0.134 & 0.341 & 28 & 0.107 & 0.315 \\
\hline Road works & 232 & 0.388 & 0.488 & 28 & 0.286 & 0.460 \\
\hline Hydraulic works & 232 & 0.306 & 0.462 & 28 & 0.321 & 0.476 \\
\hline \multicolumn{7}{|l|}{ Firm level } \\
\hline Small size & 514 & 0.158 & 0.365 & 319 & 0.160 & 0.367 \\
\hline Medium size & 514 & 0.589 & 0.492 & 319 & 0.624 & 0.485 \\
\hline Large size & 514 & 0.253 & 0.435 & 319 & 0.216 & 0.412 \\
\hline Distance firm-CA (km) & 514 & 449.463 & 448.476 & 319 & 344.765 & 391.891 \\
\hline
\end{tabular}

by 319 different firms. ${ }^{28}$ The average auction's reserve price is around 1.1 million euros in both types of auctions and the average number of participating firms per auction is about 53 in $\mathrm{AB}$ and 83 in ABL. Most of the auctions concern road works (38.8 percent of the $\mathrm{AB}$ auctions; 28.6 percent of the $\mathrm{ABL}$ auctions), hydraulic works (30.6 percent of the $\mathrm{AB}$ auctions; 32.1 percent of the ABL auctions), and building construction (13.4 percent of the $\mathrm{AB}$ auctions; 10.7 percent of the $\mathrm{ABL}$ auctions). The two samples are pretty homogeneous also looking at firms' other characteristics, such as size (about 84 percent are medium or large firms), backlog (upon bidding, firms have, on average, between two and three pending public procurement projects) and subcontracting position (on average, more than 80 percent of the firms have the option to subcontract part of the work).

\section{Main Estimation Results}

In Table 2, columns 1-3, we present our estimation results for the sample of $\mathrm{AB}$ auctions. In all specifications, the negative and statistically significant coefficient of $\log ($ BidderSoph $)$ shows that firms with a higher sophistication index tend to bid closer to $A 2$, thus supporting the prediction contained in Proposition 2. This result is robust to the inclusion of covariates at auction, firm, and firm-auction level (column 1), firm fixed effects (column 2), and firm-year fixed effects (column 3). The inclusion of fixed effects allows us to explore the within firm (or firm-year)

\footnotetext{
${ }^{28}$ We thus rely on an unbalanced panel of firms. In the $\mathrm{AB}$ sample, on average, a firm shows up in 17.37 auctions: 17.32 percent of the firms in 1 auction, 22.95 percent in 2-4 auctions, 21.99 percent in 5-10 auctions, 26.85 percent in $11-50$ auctions, 9.72 percent in 50-100 auctions, and 1.17 percent in more than 100 auctions. In the ABL sample, on average, a firm shows up in 4.7 auctions: 28.53 percent of the firms in 1 auction, 19.44 percent in 2 auctions, 10.66 percent in 3 auctions, 3.76 percent in 4 auctions, 24.14 percent in 5-10 auctions, and 13.48 percent in more than 10 auctions.
} 
TABLE 2-MAIN REsults

\begin{tabular}{|c|c|c|c|c|c|c|}
\hline \multirow{3}{*}{$\begin{array}{l}\text { Dependent variable } \\
\text { Auction format }\end{array}$} & \multicolumn{6}{|c|}{$\log \mid$ Distance $\mid$} \\
\hline & \multicolumn{3}{|c|}{$\mathrm{AB}$} & \multicolumn{3}{|c|}{$\mathrm{ABL}$} \\
\hline & (1) & $(2)$ & (3) & (4) & $(5)$ & (6) \\
\hline $\log ($ BidderSoph $)$ & $\begin{array}{r}-0.171 \\
(0.022)\end{array}$ & $\begin{array}{r}-0.170 \\
(0.038)\end{array}$ & $\begin{array}{r}-0.243 \\
(0.041)\end{array}$ & $\begin{array}{r}-0.386 \\
(0.042)\end{array}$ & $\begin{array}{r}-0.468 \\
(0.063)\end{array}$ & $\begin{array}{r}-0.522 \\
(0.073)\end{array}$ \\
\hline Firm controls & Yes & No & No & Yes & No & No \\
\hline Firm-auction controls & Yes & Yes & Yes & Yes & Yes & Yes \\
\hline Auction controls & Yes & Yes & Yes & Yes & Yes & Yes \\
\hline Firm fixed effects & No & Yes & No & No & Yes & No \\
\hline Firm year fixed effects & No & No & Yes & No & No & Yes \\
\hline Observations & 8,927 & 8,838 & 8,573 & 1,501 & 1,410 & 1,266 \\
\hline$R^{2}$ & 0.192 & 0.266 & 0.352 & 0.279 & 0.459 & 0.498 \\
\hline
\end{tabular}

Notes: OLS estimates. Robust standard errors clustered at firm level are in parentheses. Firm controls include: dummy variables for the size of the firm, and the distance between the firm and the CA. Firm-auction controls include: a dummy variable for the firm's subcontracting position (mandatory or optional), and a measure of the firm's backlog. Auction controls include: the auction's reserve price, the expected duration of the work, dummy variables for the type of work, and dummy variables for the year of the auction.

variability and to reduce selection bias and omitted variable problems: in particular, firm fixed effects can capture the role of any idyosincratic (either innate or previously acquired) component of sophistication specific to that firm/manager, while firm-year fixed effects can capture this same component also for firms whose management changed during the sample period. ${ }^{29}$

Table 2 also reports the results of the regressions for the sample of ABL auctions. Looking at this sample is illuminating because it allows us not only to test the role of firms' sophistication in a different average bid format, but also to address potential measurement error problems. In fact, while the $\mathrm{AB}$ format has long and widely been adopted in Italy to award public works, the ABL format was introduced in 2006 and only in Valle d'Aosta. Hence, while the sophistication index computed for the AB sample does not take into account that firms may have gained experience (and thus sophistication) by participating in $\mathrm{AB}$ auctions issued by other Italian CAs and/or in the past, ${ }^{30}$ these measurement error concerns are greatly reduced in the $\mathrm{ABL}$ case. Now, also the results for the ABL sample are consistent with Proposition 2: the relationship between sophistication index and the distance from $A 3$ is highly significant and negative. This is true in all the specifications, without fixed effects (column 4) and with firm or firm-year fixed effects (columns 5 and 6). Interestingly, the estimated coefficient for the sophistication index in the ABL auctions indicate a larger negative effect than in AB. A plausible explanation for this could be related to the measurement error problems just discussed. In fact, in AB auctions we might

\footnotetext{
${ }^{29}$ In the online Appendix (Tables D1 and D3), we show that our main result is confirmed also when: (i) we replace auction covariates with auction-fixed effects; (ii) we add the number of bidders as a proxy for the auction's competitive pressure; (iii) we estimate a Heckman selection model; (iv) the sophistication index is not only auction format - but also work category-specific (i.e., the sophistication acquired in one type of work is irrelevant when that firm bids in an auction for a different type of work).

${ }^{30}$ Anyhow, we believe that the impact of the experience gained outside Valle d'Aosta should be limited because the knowledge of the specificity of each market (first of all, its players) is extremely relevant. Moreover, the sophistication accumulated in the past (i.e., before year 2000) should be captured by the fixed effects.
} 
be underestimating the true level of sophistication of firms, especially the most sophisticated ones, which are also those that are most likely to bid also outside Valle d'Aosta. ${ }^{31}$

\section{E. Learning Dynamics}

The previous analysis showed that, in line with the prediction obtained from a $\mathrm{CH}$ model, there is a stable negative relationship between firms' sophistication index and the distance of their bids from $A 2$ or $A 3$. However, that analysis does not say much about the dynamics behind this relationship. In particular, do firms learn to think and bid strategically as they participate in more and more auctions? And, if so, what are the determinants and the characteristics of this learning process? Our starting point is the evidence suggested from the kernel density distribution of bids in $\mathrm{AB}$ auctions issued during the first (2000) and last (2005) year covered by our dataset. Figure 4 shows that, compared to year 2000, bids in 2005 are generally more concentrated on the right side of the distribution, thus suggesting that a learning process is most likely to be taking place.

To investigate such a process more in depth, we decompose firm $i$ 's sophistication index at auction $j$ into two components. The first component is simply the number of past participations by firm $i$ in auctions of the same format as $j$ and is meant to capture the pure role of experience; we denote this variable by PastPart. The second component, denoted by PastPerf, is the average performance of firm $i$ in all previous auctions of the same format as $j$, measured as the average of the (complement to one of the) distance of her bid from $A 2$ or $A 3 .{ }^{32}$ This variable is intended to proxy the degree at which a firm learns to think and bid strategically from her past performance. Furthermore, through the fixed effects at the firm-year level, we also implicitly take into account a third component: the stock of strategic skills of a firm/manager in any given year, both innate and acquired in the past.

Focusing on the sample of $A B$ auctions, the first two columns of Table 3 show the results obtained by estimating a regression model like (2), where the regressor $\log ($ BidderSoph $)$ is replaced by its two components: $\log$ (PastPart) and $\log ($ PastPerf $)$. Notice that in both specifications, $\log ($ PastPart $)$ has a negative and statistically significant coefficient; everything else equal, firms that participate more bid better (i.e., closer to $A 2$ ) than those that participate less. On the other hand, the coefficient attached to $\log ($ PastPerf) is negative without firm-year fixed effects (column 1), but becomes positive when we control for firms' idiosyncratic skills (column 2). This evidence suggests that a firm's learning over time seems to be driven by the number of past bids and that, at least in $\mathrm{AB}$ auctions, a firm tends to learn more from a poor than from a good past performance, as if a firm that performs well in one auction fails to recognize that thanks to experience, her competitors are likely to improve their strategic reasoning in the next one.

\footnotetext{
${ }^{31}$ We thank an anonymous referee for suggesting this interpretation.

${ }^{32}$ In symbols (for the $\mathrm{AB}$ format): PastPart ${ }_{i j}^{A B}=\left|\mathcal{A B}_{i j}\right|$, where $\left|\mathcal{A B}_{i j}\right|$ is the cardinality of $\mathcal{A B}_{i j}$, and PastPerf $_{i j}^{A B}=$ BidderSoph $_{i j}^{A B} /$ PastPart $_{i j}^{A B}$. In other words, PastPerf is equal to the sophistication index over the number of participations. Notice that the correlation between PastPerf and BidderSoph is equal to 0.23.
} 


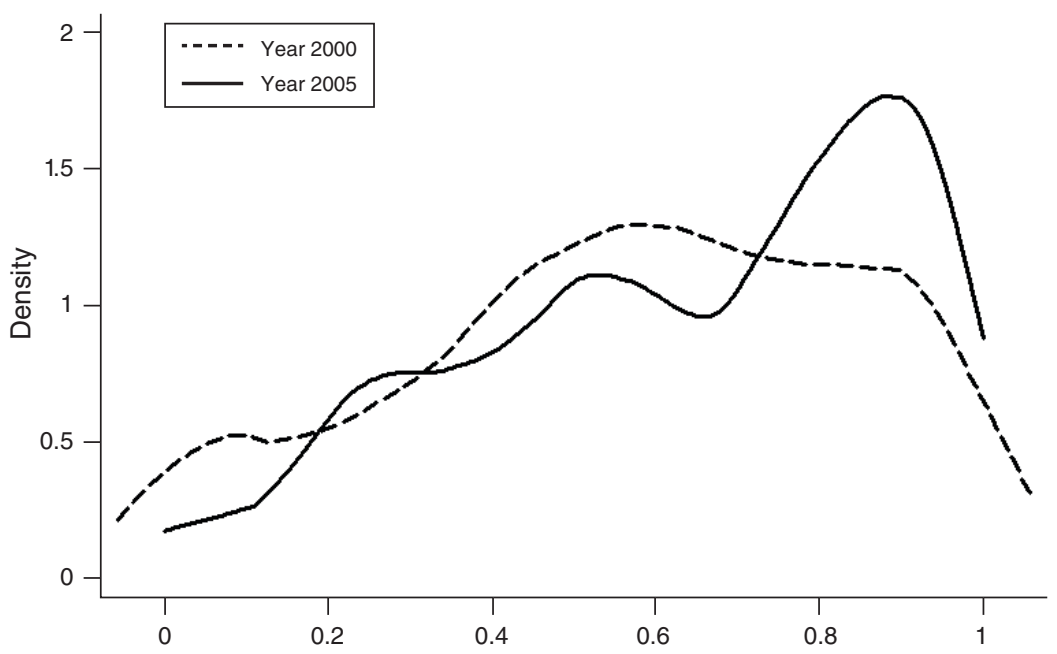

Normalized bids for each auction: $0=\min$ bid; $1=\max$ bid

Figure 4. Discounts in Year 2000 and 2005: Kernel Density Estimation

TABle 3-Learning DyNamics

\begin{tabular}{|c|c|c|c|c|c|c|c|c|}
\hline \multirow{3}{*}{$\begin{array}{l}\text { Dependent variable } \\
\text { Auction format }\end{array}$} & \multicolumn{8}{|c|}{$\log \mid$ Distance $\mid$} \\
\hline & \multicolumn{4}{|c|}{$\mathrm{AB}$} & \multicolumn{4}{|c|}{$\mathrm{ABL}$} \\
\hline & (1) & (2) & (3) & (4) & (5) & (6) & (7) & (8) \\
\hline $\log ($ PastPart $)$ & $\begin{array}{c}-0.114 \\
(0.022)\end{array}$ & $\begin{array}{r}-0.428 \\
(0.045)\end{array}$ & & & & & & \\
\hline $\log ($ PastPerf $)$ & $\begin{array}{c}-0.798 \\
(0.081)\end{array}$ & $\begin{array}{c}0.908 \\
(0.181)\end{array}$ & & & & & & \\
\hline $\log (1+$ PastWins $)$ & & & $\begin{array}{c}0.665 \\
(0.166)\end{array}$ & $\begin{array}{c}0.555 \\
(0.164)\end{array}$ & & & & \\
\hline $\log (1+$ PastDefeats $)$ & & & $\begin{array}{c}-0.551 \\
(0.059)\end{array}$ & & & & & \\
\hline $\log ($ BidderSoph $)$ & & & & $\begin{array}{r}-0.293 \\
(0.046)\end{array}$ & & $\begin{array}{r}-0.410 \\
(0.046)\end{array}$ & & $\begin{array}{r}-0.406 \\
(0.047)\end{array}$ \\
\hline $\log ($ BidderSophAB $)$ & & & & & $\begin{array}{r}-0.083 \\
(0.045)\end{array}$ & $\begin{array}{r}-0.010 \\
(0.049)\end{array}$ & & \\
\hline $\log ($ PastPart $A B)$ & & & & & & & $\begin{array}{c}-0.054 \\
(0.048)\end{array}$ & $\begin{array}{c}0.011 \\
(0.054)\end{array}$ \\
\hline $\log ($ PastPerfaB $)$ & & & & & & & $\begin{array}{c}-0.775 \\
(0.397)\end{array}$ & $\begin{array}{r}-0.542 \\
(0.388)\end{array}$ \\
\hline Firm controls & Yes & No & No & No & Yes & Yes & Yes & Yes \\
\hline Firm-auction controls & Yes & Yes & Yes & Yes & Yes & Yes & Yes & Yes \\
\hline Auction controls & Yes & Yes & Yes & Yes & Yes & Yes & Yes & Yes \\
\hline Firm year fixed effects & No & Yes & Yes & Yes & No & No & No & No \\
\hline Observations & 8,927 & 8,573 & 8,573 & 8,573 & 1,323 & 1,323 & 1,323 & 1,323 \\
\hline$R^{2}$ & 0.200 & 0.358 & 0.357 & 0.353 & 0.232 & 0.285 & 0.235 & 0.287 \\
\hline
\end{tabular}

Notes: OLS estimates. Robust standard errors clustered at firm level are in parentheses. Firm controls include: dummy variables for the size of the firm, and the distance between the firm and the CA. Firm-auction controls include: a dummy variable for the firm's subcontracting position (mandatory or optional) and a measure of the firm's backlog. Auction controls include: the auction's reserve price, the expected duration of the work, dummy variables for the type of work, and dummy variables for the year of the auction. 
To get deeper evidence on the learning process, we investigate whether the fact of winning an auction plays any role. To this end, we introduce the number of past wins $(\log (1+$ PastWins $))$ and past defeats $(\log (1+$ PastDefeats $))$ in our model specification. Results for the $\mathrm{AB}$ auctions indicate that, similarly to what happens with PastPerf, a firm seems to learn more from her failures than from her successes (see Table 3, columns 3 and 4). ${ }^{33}$

The results for the ABL sample ${ }^{34}$ confirm that experience improves future bidding performance (the coefficient of $\log$ (PastPart) is negative and significant) and that, between firms, a better average performance in the past is accompanied by bids closer to optimality in the future (without fixed effects, the coefficient of $\log ($ PastPerf $)$ is always negative and significant). However, differently from the AB sample, when fixed effects are included, $\log ($ PastPerf $)$ and $\log (1+$ PastWins $)$ are nonsignificant. This last fact is probably not surprising, as the winner in an ABL auction is determined randomly. Hence, the fact of winning produces less information than in the $\mathrm{AB}$ format.

To sum up, the dynamics suggested by Figure 4 are essentially the result of an experience-driven learning process; firms improve their capacity of bidding strategically as they participate in more and more auctions. As a consequence, their bids tend to be closer and closer to the optimality point. Intuitively, this effect may operate through two channels: experience may help less sophisticated bidders learn that an additional step of strategic reasoning (or, maybe, more than one) is needed; at the same time, by participating in more and more auctions, firms may be able to get a clearer picture of the sophistication levels of the competitors. This analysis also allows us to exclude that the relationship we uncovered between the sophistication index and bidding performance is simply due to inertia in bidding over time; the effect of experience on strategic bidding implies that those firms that participate more can eventually become more sophisticated than those that participate less, even if the latter were better strategic thinkers initially. Notice, on the other hand, that the set of participating firms in our sample is far from being stable. Hence, whenever a new, unexperienced firm enters, maybe replacing a more sophisticated one, the convergence process is slowed down.

Given the peculiarity of our dataset characterized by a change in the auction format, and given the results about the learning dynamics just illustrated, it is interesting to understand whether firms in ABL auctions drew lessons from what they learned in the $\mathrm{AB}$ auctions. Recall that our sophistication index was, by construction, auction format-specific, in the sense that participations to $\mathrm{AB}$ do not contribute to firms' sophistication when they bid in ABL. Hence, answering to this question is an indirect way to test how restrictive this assumption is. To this end, we focus on the sample of ABL auctions and introduce in our model (2) an additional variable, BidderSoph $A B$, representing, for each firm, the level of the sophistication index at the end of the period of $\mathrm{AB}$ auctions. Table 3, column 5, shows that a higher

\footnotetext{
${ }^{33}$ For further results on the AB sample, see the online Appendix (Table D2). Notice that we use $\log (1+$ PastWins $)$ because PastWins has a lot of zeros. The coefficient attached to $\log (1+$ PastWins $)$ is the elasticity of $\mid$ Distance $\mid$ with respect to $(1+$ PastWins), which is larger (in absolute value) than the elasticity with respect to PastWins. For consistency, we also use $\log (1+$ PastDefeats $)$.

${ }^{34}$ These results are reported in the online Appendix (Table D4).
} 
sophistication index achieved in the $\mathrm{AB}$ period is associated with a lower distance from $A 3$ in ABL. However, when we re-introduce (in column 6) the firm's sophistication associated to the ABL auctions (BidderSoph), the coefficient of the former index is not statistically different from zero, while the auction-specific one is still negative and statistically significant. This result suggests that what really matters is the firm's strategic ability acquired in that specific type of auction.

Similar results are obtained when we introduce in the model specification the number of participations (PastPartAB) and the average past performance (PastPerfAB) in $\mathrm{AB}$ auctions (columns 7 and 8). The coefficients of these two variables are not significant, once we control for the ability acquired by the firm in the ABL auctions.

\section{Discussion}

The analysis presented in the previous section provides evidence that supports, at least qualitatively, a nonequilibrium model of bidding behavior by firms in average bid auctions: observed deviations from the optimal bid are related to a measure of firms' capacity of bidding strategically, the sophistication index; this relation goes in the direction predicted by a $\mathrm{CH}$ model. Therefore, our (continuous) sophistication index proxies the (discrete) $\mathrm{CH}$-level of sophistication by firms. The analysis showed that the relation between sophistication index and bidding behavior is robust to a number of determinants, including auction's, firm's and firm-auction's specific characteristics. Most importantly, the relation holds also when we analyze the ABL format, which is new to the firms and characterized by a stochastic component that makes it more complicated for firms to formulate their bidding strategies.

In this section, we show that our explanation is robust to a number of issues that, potentially, may undermine it. In particular, we discuss: (i) whether our sophistication index, which we interpret as a measure of strategic thinking ability, may be actually capturing other firms' structural factors, in particular their competitiveness; (ii) the role of potential cartels jointly bidding in the auctions; (iii) additional empirical evidence to rule out alternative explanations.

\section{A. Strategic Ability versus Competitiveness}

In standard procurement auctions, the main determinant of a firm's bid is her production cost: more competitive firms can and do make more aggressive offers, outbidding less competitive ones. A natural question that arises in our context is whether our sophistication index, which, in our view, proxies strategic ability, actually captures some structural competitive feature of the firm: productivity, proximity, or, more generally, any element that translates into a cost advantage. Now, notice first that, in our main empirical exercise, we alternatively control for firm's characteristics (such as size and distance between the firm headquarter and the CA), firm fixed effects, or firm-year fixed effects, as well as for the firm's subcontracting position (whether the firm must subcontract part of the work or not) and for the number of pending projects the firm is involved in at the time of bidding (which 
captures her productive capacity). ${ }^{35}$ Most factors that may generate a competitive advantage/disadvantage of one firm over the others are likely to be accounted for by these variables.

However, one might argue that we do not fully control for factors that, similarly to the sophistication index, can vary for each firm within a year or for different types of projects. To shed light on these questions, we first estimated a model which includes firm-year-category of work-fixed effects and one with firm-semester-fixed effects: in both models, the coefficient of $\log ($ BidderSoph $)$ in $\mathrm{AB}$ auctions is very much in line with that of our main model specification (see Table 4, columns 1 and 2). ${ }^{36}$

Second, we performed an analysis on the level of bids. We start from the conjecture that, if the sophistication index were actually capturing some cost advantage, we would expect to observe either a positive or a null relation between the sophistication index and the level of a firm's bid. In fact, irrespective of the auction format and of the submitted bid, if a firm's costs are binding (in the sense that, had her costs been lower, she would have made a different bid), a cost reduction would necessarily result in a higher bid; if, instead, her costs are not binding, a further cost reduction should have no impact on her bid. On the other hand, if our sophistication index captures strategic ability, as we claim, we would expect to observe a negative [positive] relationship between the sophistication index and the bid level for firms making relatively high [low] bids. In fact, in average bid auctions, an improvement in strategic ability would lead firms that bid too high [low] to reduce [increase] their bids toward the optimal bid, which is necessarily somewhere in the interior of the range of submitted bids. Now, focusing on the $\mathrm{AB}$ sample, our evidence is indeed in line with the latter interpretation and inconsistent with the one based on cost advantage: the effect of the sophistication index on the level of bids, though nonsignificant overall (see Table 4, column 3), is negative and significant for those firms bidding the highest (see Table 4 , column 4 , where the results of a regression at the ninetieth quantile are reported). ${ }^{37}$

\section{B. Potential Collusion}

A very interesting aspect that is worth addressing is related to possible collusive behaviors by firms. In a recent paper, Conley and Decarolis (2016), using a different dataset of $\mathrm{AB}$ auctions, argue that this format can be characterized by the presence

\footnotetext{
${ }^{35}$ Jofre-Bonet and Pesendorfer (2003), using a dataset of a sequence of first-price procurement auctions for highway construction in California, showed that the outcome of one auction may affect bids in successive ones because the winner of a previous auction, having committed some or all of her capacity, may have larger costs when participating in the next auctions (because, for example, it will have to rent additional equipment). In our context, this dynamic component seems to be absent, as the variable Backlog-the number of pending public procurement projects that a firm has at the moment of bidding - is never significant. Our intuition is that, even though it is plausible that having committed capacity can affect firms' costs, costs simply do not matter much for (optimal) bidding in average bid auctions.

${ }^{36}$ Our result is robust also to the inclusion of firm-semester-category of work-fixed effects. Due to the smaller sample dimension, results are slightly weaker for the ABL format (see the online Appendix, Table D5).

${ }^{37}$ See the online Appendix (Tables D6 and D7) for evidence on ABL auctions and further evidence at different quantiles of the distribution of bids. Notice that, in both formats, the coefficients of the sophistication index in the quantile regressions exactly match the pattern predicted by a $\mathrm{CH}$ model: they are negative [positive] and statistically significant for high [low] bid levels.
} 
TABLE 4-IDENTIFICATION IsSUES

\begin{tabular}{|c|c|c|c|c|c|c|}
\hline \multirow{4}{*}{$\begin{array}{l}\text { Auction format } \\
\text { Dependent variable } \\
\text { Quantile }(t h)\end{array}$} & \multicolumn{6}{|c|}{$\mathrm{AB}$} \\
\hline & \multicolumn{2}{|c|}{$\log \mid$ Distance $\mid$} & \multicolumn{2}{|c|}{$\log ($ Discount $)$} & \multicolumn{2}{|c|}{$\log \mid$ Distance $\mid$} \\
\hline & & & & 90 & & \\
\hline & $(1)$ & $(2)$ & (3) & (4) & $(5)$ & (6) \\
\hline $\log ($ BidderSoph $)$ & $\begin{array}{r}-0.243 \\
(0.045)\end{array}$ & $\begin{array}{r}-0.137 \\
(0.047)\end{array}$ & $\begin{array}{r}-0.016 \\
(0.013)\end{array}$ & $\begin{array}{r}-0.003 \\
(0.001)\end{array}$ & $\begin{array}{r}-0.282 \\
(0.042)\end{array}$ & $\begin{array}{r}-0.228 \\
(0.061)\end{array}$ \\
\hline $\log ($ GroupMembers $)$ & & & & & $\begin{array}{r}-0.251 \\
(0.053)\end{array}$ & \\
\hline Firm controls & No & No & No & Yes & No & No \\
\hline Firm-auction controls & Yes & Yes & Yes & Yes & Yes & Yes \\
\hline Auction controls & Yes & Yes & Yes & Yes & Yes & Yes \\
\hline Firm-year-category of work-FE & Yes & No & No & No & No & No \\
\hline Firm-semester-FE & No & Yes & No & No & No & No \\
\hline Firm-year-FE & No & No & Yes & No & Yes & Yes \\
\hline Observations & 8,068 & 8,208 & 8,573 & 8,927 & 7,794 & 3,716 \\
\hline$R^{2}$ & 0.413 & 0.408 & 0.422 & 0.189 & 0.343 & 0.410 \\
\hline
\end{tabular}

Notes: OLS estimates are in columns 1-3 and 5-6. Quantile regression is in column 4. Robust standard errors clustered at firm level are in parentheses. Firm controls include: dummy variables for the size of the firm, and the distance between the firm and the CA. Firm-auction controls include: a dummy variable for the firm's subcontracting position (mandatory or optional), and a measure of the firm's backlog. Auction controls include: the auction's reserve price, the expected duration of the work, dummy variables for the type of work, and dummy variables for the year of the auction.

of colluding firms which drive the winning threshold to let one member of the cartel win. Hence, the evidence on AB auctions would be the result of a cooperative behavior by groups of firms. Instead, our approach is totally different: we cannot exclude the presence of colluding firms, but we provide some evidence that also a fully noncooperative nonequilibrium behavior might be at work. In this sense, our work suggests a complementary explanation. Nevertheless, we can provide some arguments supporting the robustness of our findings to the presence of collusion.

First, it seems reasonable to assert that, if collusion is at work, it is less likely to be present in ABL than in $\mathrm{AB}$ auctions: given the inherent uncertainty in the determination of the winning firm, in ABL a successful collusive strategy is much more complicated to be implemented. In this sense, the fact that the coefficient of the sophistication index is significant also in ABL and larger than in $\mathrm{AB}$ (see Table 2) is reassuring for our explanation.

Second, without any intention to provide evidence on the presence of cartels in the auctions issued by the Regional Government of Valle d'Aosta (note that, unlike in Conley and Decarolis (2016), in our sample no cartels have been detected and sanctioned by the court; this makes it more difficult to study possible collusive behavior in our setting), we tried to isolate the influence of potential collusive groups. To this end, we identified potential cartels following Conley and Decarolis (2016). In particular, using information on objective links among firms (e.g., firms sharing the same managers, the owners, the location, subcontracting relationship, joint bidding, etc.), the Conley and Decarolis' algorithm indicates that, in our sample, 172 potential groups of firms are present. After detecting these groups, we added to 
our baseline model specification one variable, $\log$ (GroupMembers), measuring, for each firm $i$ and each auction $j$, how many firms belonging to the same (potential) group of $i$ (including $i$ herself) are bidding in auction $j$. Our main results continue to hold after the inclusion of this control (see Table 4, column 5). ${ }^{38}$ It must be observed that data display a (weak) positive correlation between the sophistication index and the number of (potentially) associated firms bidding in that auction, both in AB (0.144) and in ABL (0.188) auctions. Moreover, independent firms-those with no potential associates in the auction-show, on average, lower sophistication than associated firms (the difference is about 26 percent in $\mathrm{AB}$ and 31 percent in $\mathrm{ABL}$ ): these numbers may suggest that, if cartels are present, their members are typically more sophisticated than independent firms. Now, to better isolate the role of potential collusion from that of strategic ability, we estimated our baseline model on a restricted sample including only firms with no connection with any other firm participating in that auction (Table 4, column 6). Again, our main result is confirmed, thus supporting the idea that our explanation actually captures bidding behavior by firms, at least for those that act non-cooperatively.

\section{Further Evidence}

Beyond the main result that more sophisticated firms bid closer to $A 2$ in $\mathrm{AB}$, to $A 3$ in $\mathrm{ABL}$, there is additional evidence that supports our interpretation, in the sense that it can easily be reconciled within a $\mathrm{CH}$ model, much less so within alternative explanations. ${ }^{39}$

First, notice that firms make relatively lower bids in $A B L$ than in $A B$ : this is clear from our data (see Figure 2); furthermore, if we run a regression on a sample of (min-max rescaled) bids offered both in $\mathrm{AB}$ and $\mathrm{ABL}$ auctions (taking all the covariates included in equation (2)), the coefficient for the ABL auction dummy is negative and statistically significant. ${ }^{40}$ Now, if firms were making equilibrium bids, we should observe the opposite (see Proposition 1); instead, in a $\mathrm{CH}$ model, given the behavior of level 0 firms, bids made by firms of higher levels are larger in $\mathrm{AB}$ than in ABL, since, by definition, $A 2_{k}$, the (asymptotically) optimal bid by a level$(k+1)$ firm in $\mathrm{AB}$, is larger than $A 3_{k}$.

Second, data show that not only the average distance from $A 2$ or $A 3$ is decreasing in the firm's sophistication level, but also the variance of this distance follows the same pattern. In fact, running a regression where the dependent variable is the standard deviation of the distance of the auction's bids from $A 2$ or $A 3$, the coefficient of

\footnotetext{
${ }^{38}$ Further results for this analysis are available in the online Appendix (Tables D8 and D9).

${ }^{39}$ This evidence is collected in the online Appendix (Table D10).

${ }^{40}$ Notice that even if we cannot fully separate in a difference-in-differences style, the trend forces from the effects related to the introduction of the (new) ABL auction format in Valle d'Aosta (as we do not observe AB auctions after 2005), evidence based on a larger sample of procurement auctions (data from Coviello et al. 2018) indicate that for other Italian regions not adopting the ABL auction format, the average winning discount in 2006 is approximately at the same level as in 2005, or it has increased for some Northwestern regions. Given that between 2005 and 2006 no major changes occurred in Valle d'Aosta's economy conditions and in the procurement regulation (other than the introduction of ABL auction format), we can assume that, had Valle d'Aosta not introduced the ABL auction, the trend would have followed a nondecreasing path similar to the one observed in the other regions.
} 
the auction's average sophistication index is negative and significant in both formats. Moreover, in a regression where the dependent variable is the rolling standard deviation of the distance of a firm's latest five bids from $A 2$ or $A 3$, the coefficient of the firm's rolling average sophistication index is negative and significant, even when firm fixed effects are controlled for. Now, while there is no particular reason to expect a relationship between variance of bidding and other firm's characteristics (e.g., her production costs), a negative relationship between sophistication index and variance of bidding can be justified within a $\mathrm{CH}$ model with at least three arguments: (i) in a $\mathrm{CH}$ model, level-0 firms bid randomly, while more sophisticated firms bid (essentially) deterministically; (ii) if firms make some payoff-sensitive errors, ${ }^{41}$ then more sophisticated firms will make more precise bids (with less variance). The intuition is simple: to compute her optimal bid, a level- $k$ firm estimates the distribution of the winning threshold on the basis of the behaviors of level- 0 to level- $(k-1)$ firms. For higher level firms, this distribution has lower variance, being less and less affected by the random behavior of level-0 firms; (iii) it seems reasonable to believe that more sophisticated firms are less prone to errors than less sophisticated ones.

Third, data show that the higher the number of participating firms in an auction, the higher [the lower] the value of $A 2[A 3]$ in $\mathrm{AB}[\mathrm{ABL}]$. This can be seen by looking at descriptive statistics (the simple correlation between the number of participants and $A 2[A 3]$ in $\mathrm{AB}[\mathrm{ABL}]$ is positive [negative]) and by estimating a regression with $A 2$ or $A 3$ as the dependent variable and the number of participants and other auction-level controls as regressors. This evidence is consistent with a $\mathrm{CH}$ model of bidding behavior: in the viewpoint of a sophisticated firm, who determines her bid on the basis of her own estimates of the distribution of $A 2$ or $A 3$, a lower number of participants increases the variance of this distribution. Since the winning bid is the one that gets closer to the winning threshold from below in $\mathrm{AB}$ and from above in ABL, a sophisticated firm will find it optimal to bid cautiously: in $\mathrm{AB}$, a little below the expected value of $A 2$, in $\mathrm{ABL}$ a little above the expected value of $A 3$. As the number of participants increases, the variance of $A 2$ or $A 3$ will reduce, and sophisticated firms can be more confident in bidding very close to their expected values.

\section{Conclusion}

This paper studies bidding behavior by firms in two versions of average bid auctions adopted by a regional contracting authority in Italy for the procurement of public works. Our empirical evidence is inconsistent with Nash equilibrium behavior, a situation in which each firm is playing her best response to other firms' bids. We proposed an interpretation based on a nonequilibrium $\mathrm{CH}$ model of bidding behavior; more sophisticated firms, being better strategic thinkers, are able to get more accurate beliefs on the behavior of other firms and bid closer to optimality. Introducing a dynamic measure of sophistication that takes into account the goodness of a firm's bids in all past auctions of the same format in our sample, we showed that the main

\footnotetext{
${ }^{41}$ See the simulation exercise in the online Appendix.
} 
prediction of the $\mathrm{CH}$ model is consistent with our data. We also investigated whether and how firms learn to think and bid strategically through experience, showing that the number of participations is the main predictor of firms' performance in future auctions and that this learning process produces a certain convergence of bids. We finally discussed identification issues and alternative explanations for the observed behavior in the investigated setting (in particular, collusion), providing some robustness checks on our empirical analysis.

The general lesson that can be learned from our work is twofold. First, our paper provides evidence that departures from equilibrium can be significant and persistent also in the field, and even when players are firms and stakes are large. This is likely to be the case especially in complex environments, for example, when the profit of one firm depends in a non-obvious way on the decisions made by all other firms. In this case, the equilibrium requirement that all players (firms) have correct beliefs seems particularly, and maybe unrealistically, demanding.

Second, the $\mathrm{CH}$ model and, more generally, models that take into account that strategic thinking may be heterogeneously distributed across economic agents, represent a valid alternative to equilibrium models in complex games, even outside the lab. Moreover, while in line with the experimental literature on $\mathrm{CH}$ models, our evidence strongly supports the idea that players improve their sophistication, as they repeatedly face the same strategic situation, this does not necessarily imply that we should expect quick convergence to equilibrium in real world games. In fact, even a small change in the environment, as the one from the $\mathrm{AB}$ to the $\mathrm{ABL}$ format, may largely reset the capacity of thinking strategically previously acquired. Second, unlike in the lab, in the field, the set of players can change continuously over time; new unexperienced firms may enter the stage, others may exit. Hence, even though experience helps firms become more and more sophisticated, the entry of unsophisticated firms may slow down the convergence process.

\section{REFERENCES}

Albano, Gian Luigi, Milo Bianchi, and Giancarlo Spagnolo. 2006. "Bid Average Methods in Procurement." Rivista di Politica Economica 96 (1): 41-62.

- Brañas-Garza, Pablo, Teresa García-Muñoz, and Roberto Hernán González. 2012. "Cognitive Effort in the Beauty Contest Game." Journal of Economic Behavior and Organization 83 (2): 254-60.

- Brown, Alexander L., Colin F. Camerer, and Dan Lovallo. 2012. "To Review or Not to Review? Limited Strategic Thinking at the Movie Box Office." American Economic Journal: Microeconomics 4 (2): $1-26$.

Bucciol, Alessandro, Ottorino Chillemi, and Giacomo Palazzi. 2013. "Cost overrun and auction format in small size public works." European Journal of Political Economy 30: 35-42.

-Burnham, Terence C., David Cesarini, Magnus Johannesson, Paul Lichtenstein, and Björn Wallace. 2009. "Higher cognitive ability is associated with lower entries in a $p$-beauty contest." Journal of Economic Behavior and Organization 72 (1): 171-75.

-Camerer, Colin F., Teck-Hua Ho, and Juin-Kuan Chong. 2004. "A Cognitive Hierarchy Model of Games." Quarterly Journal of Economics 119 (3): 861-98.

Cameron, Lisa J. 2000. "Limiting Buyer Discretion: Effects on Performance and Price in Long-Term Contracts." American Economic Review 90 (1): 265-81.

-Chang, Wei-Shiun, Bo Chen, and Timothy C. Salmon. 2015. "An Investigation of the Average Bid Mechanism for Procurement Auctions." Management Science 61 (6): 1237-54.

-Chen, Shu-Heng, Ye-Rong Du, and Lee-Xieng Yang. 2014. "Cognitive capacity and cognitive hierarchy: A study based on beauty contest experiments." Journal of Economic Interaction and Coordination 9 (1): 69-105. 
Conley, Timothy G., and Francesco Decarolis. 2016. "Detecting Bidders Groups in Collusive Auctions." American Economic Journal: Microeconomics 8 (2): 1-38.

Coviello, Decio, and Mario Mariniello. 2014. "Publicity requirements in public procurement: Evidence from a regression discontinuity design." Journal of Public Economics 109: 76-100.

Coviello, Decio, Luigi Moretti, Giancarlo Spagnolo, and Paola Valbonesi. 2018. "Court Efficiency and Procurement Performance." Scandinavian Journal of Economics 120 (3): 826-58.

-Crawford, Vincent P., Miguel A. Costa-Gomes, and Nagore Iriberri. 2013. "Structural Models of Nonequilibrium Strategic Thinking: Theory, Evidence, and Applications.” Journal of Economic Literature 51 (1): 5-62.

Crawford, Vincent P., and Nagore Iriberri. 2007. "Level- $k$ Auctions: Can a Nonequilibrium Model of Strategic Thinking Explain the Winner's Curse and Overbidding in Private-Value Auctions?" Econometrica 75 (6): 1721-70.

Decarolis, Francesco. 2014. "Awarding Price, Contract Performance, and Bids Screening: Evidence from Procurement Auctions." American Economic Journal: Applied Economics 6 (1): 108-32.

-Decarolis, Francesco. 2018. "Comparing Public Procurement Auctions." International Economic Review 59 (2): 391-419.

Galavotti, Stefano, Luigi Moretti, and Paola Valbonesi. 2018. "Sophisticated Bidders in Beauty-Contest Auctions: Dataset." American Economic Journal: Microeconomics. https://doi.org/10.1257/ mic. 20150240.

Gill, David, and Victoria Prowse. 2016. "Cognitive Ability, Character Skills, and Learning to Play Equilibrium: A Level-k Analysis.” Journal of Political Economy 124 (6): 1619-76.

Gillen, Benjamin J. 2009. "Identification and Estimation of Level-k Auctions.” https://papers.ssrn.com/ sol3/papers.cfm?abstract_id $=1337843$.

Goldfarb, Avi, and Mo Xiao. 2011. "Who Thinks about the Competition? Managerial Ability and Strategic Entry in US Local Telephone Markets." American Economic Review 101 (7): 3130-61.

-Goldfarb, Avi, and Botao Yang. 2009. "Are All Managers Created Equal?" Journal of Marketing Research 46 (5): 612-22.

Hendricks, Kenneth, and Robert H. Porter. 1988. "An Empirical Study of an Auction with Asymmetric Information." American Economic Review 78 (5): 865-83.

Hendricks, Kenneth, Robert H. Porter, and Bryan Boudreau. 1987. "Information, Returns, and Bidding Behavior in OCS Auctions: 1954-1969." Journal of Industrial Economics 35 (4): 517-42.

Hortaçsu, Ali, Fernando Luco, Steven L. Puller, and Dongni Zhu. 2017. "Does Strategic Ability Affect Efficiency? Evidence from Electricity Markets." National Bureau of Economic Research (NBER) Working Paper 23526.

- Jofre-Bonet, Mireia, and Martin Pesendorfer. 2003. "Estimation of a Dynamic Auction Game." Econometrica 71 (5): 1443-89.

Moretti, Luigi, and Paola Valbonesi. 2015. "Firms' Qualifications and Subcontracting in Public Procurement: An Empirical Investigation." Journal of Law, Economics, and Organization 31 (3): 568-98.

Nagel, Rosemarie. 1995. "Unraveling in Guessing Games: An Experimental Study." American Economic Review 85 (5): 1313-26.

-Stahl, Dale O., II, and Paul W. Wilson. 1994. "Experimental evidence on players' models of other players." Journal of Economic Behavior and Organization 25 (3): 309-27.

-Stahl, Dale O., II, and Paul W. Wilson. 1995. "On Players' Models of Other Players: Theory and Experimental Evidence." Games and Economic Behavior 10 (1): 218-54.

Zheng, Charles Z. 2001. "High Bids and Broke Winners.” Journal of Economic Theory 100 (1): 129-71. 